\title{
A STRATEgic Framework For MobiLe PAYMENTS
}

\author{
Sitalakshmi Venkatraman \\ School of Engineering, Construction and Design (IT), Melbourne Polytechnic, Australia
}

\begin{abstract}
With the exponential proliferation of mobile devices, smart phones and apps in the consumer market, mobile payment is emerging as a key area to revolutionise the everyday financial life of both consumers and merchants. The past few years have witnessed an increase in the adoption of digital payments and online billing methods that leverage on wireless technologies and the Internet. However, the success or failure of mobile payments in businesses is a hot topic today due to the multi-faceted factors such as, type of wireless technologies used, security and privacy, the players involved and their influencing business models, including consumer factors relating to interoperability, flexibility, ease-of-use and social marketing. This paper examines mobile payments in all perspectives: technical, social as well as business viewpoints and provides a strategic framework for a successful mobile payment adoption.
\end{abstract}

\section{KEYWORDS}

Mobile payments, Wireless technologies, Business models. Smart phones, Mobile Apps, M-commerce

\section{INTRODUCTION}

Wireless e-business termed as m-commerce has the main advantage of portability with ubiquitous business transactions that can be performed anywhere and anytime [1]. In addition to the key mobile features of location-based and personalised information services, payments embedded in mobile apps or websites provide value-added facility that aid in the business agility of organisations in this competitive business environment [2][3]. With recent developments in wireless communication technologies using $3 \mathrm{G}$ evolved to $4 \mathrm{G}$ networks, mobile Internet and multimedia streaming have gained popularity and provide increased channels of interaction with customers [4][5]. Hence, organisations expect that m-commerce provides a cost-effective improvement in their operational efficiency, resulting in an increase in profitability. Businesses have started to consider mobile payments as value-added services providing opportunities for their marketing, promotion and branding that leverage on social media [6][7].

Apart from business perspectives, looking at consumer trend in the last decade, most consumers have been using mobile phones beyond the traditional services of voice calls and SMS. By the end of 2016, two thirds of the world's population acquired a mobile subscription with a surge in mobile broadband adoption via smart phones [8]. Mobile devices now account for $60 \%$ of the connections with new services and dedicated apps leveraging on mobile internet that could make common man's daily activities quite convenient. Hence, consumers' expectations from these smart devices have risen dramatically and mobile payment services are now being recognised to be important. Many consumers from countries such as, Finland, UK, North America, Japan, Korea and Singapore started to adopt mobile payments more than a decade back [9][10] as their preferred mode of cashless transactions in their everyday lives - while transacting with vending machines, online ticketing agencies, public transport systems and merchant stores. A recent survey in UK indicates that $56 \%$ of smart phone owners purchased a product using a mobile app 
transaction in 2015 and mobile banking transactions via apps have now been envisaged by consumers [11]. However, global reports indicate that mobile revenue growth is slow [8][12]. There is lack of research in analysing this situation from current technological, business and social perspectives and such investigations could have a positive influence on mobile payment adoption [7][13]. This provides the key motivation for the study reported here.

This paper is aimed at providing an analysis of the trends in mobile payments, from technology, business, as well as consumer perspectives in order to arrive at a strategic framework for adopting mobile payments successfully. The remainder of the paper is organised as follows. Section 2 describes the need for the study. The influencing factors from various facets of mobile payments are identified and analysed in section 3. Resulting from a detailed analysis, a set of strategies are identified and a framework is proposed for mobile payment adoption in section 4. Finally, concluding remarks are provided in section 5.

\section{The NeEd For The STUDY}

Despite potential advantages of m-commerce], mobile payments face major challenges as financial transactions via mobile devices demands a multi-faceted approach involving technology innovations, apps and service offerings, global business trends as well as social impacts [14][15]. In addition, with the emergence of player-centric mobile payment services, new mobile payment business models are being introduced [16]. Both remote and proximity type of mobile payment systems have witnessed evolution of technologies such as Infrared (IR) and Bluetooth combined with services such as Interactive Voice Response (IVR), Short Message Service (SMS), Radio Frequency Identification (RFID)/2D bar codes, Wireless application Protocol (WAP), contactless interface to chip-enabled payment technology, Near-Field Communication (NFC) enabled mobile phones, contactless stickers, tags, mobile browsers, mobile apps and m-wallets [5][17].

With the existing plethora of wireless technologies, both merchants and consumers are clouded with a range of options available to them for adopting mobile payments and are not sure if they are taking the road to success or failure [4][7]. In the past decade, mobile payments were used for predominantly non-banking transactions with several failed initiatives such as Dencoin and Google Wallet even in developed countries [18][19]. Thus, it lies in the strategic creation of 'new efficiencies' to be considered in a payment system that benefits all stakeholders involved in a mobile payment transaction. One must clearly understand the complexities of the key dimensions of mobile payments: various players involved in mobile payment systems, the different mobile payment/billing methods, the numerous wireless technologies or infrastructure supporting these payment services and the more recent developments in social marketing.

On one hand, the banking sector is gradually embracing digital payments capitalising on the IT players such as Apple and Google to compete in the market that may shape its future [12]. On the other hand, the success or failure of mobile payments is based on the social performance of the market and consumer acceptance [13]. Recent studies conducted worldwide indicate that mobile payment growth has been slower than anticipated [8][12]. This is because, mobile payments are not just a new technology added on to existing consumer networks, but actually have their own set of historical and normative roots in development practices with an emphasis to be given on market subjects and consumer subjects [7]. Previous studies have predominantly focussed on the technology and payment options available to a consumer based on factors such as location (remote/proximity), payment value (micro/macro amount), and charging method (post-paid/prepaid), and the associated security protocols [20][21][22]. There is lack of literature that analyses the current multi-faceted dimensions of mobile payments [23][24]. There is little guidance available for merchants and consumers to review the various mobile payment options and to adopt those mobile payment methods that suit their requirements. 
Due to the paucity of research in this area, this paper proposes a framework for considering various strategies for successfully adopting mobile payments. There is a need to learn and enhance from previous studies conducted to identify how issues have evolved over a decade [25][26][27][28]. This paper embraces such an approach in order to identify and consolidate a set of key sustainable strategies from technical, business and social viewpoints, which would serve as a guideline for mobile payment adoption of the future. Investigating the influencing factors from these viewpoints would help businesses and consumers to make a more systematic review before they embark on the right kind of mobile payments that would add value to their everyday activities. This research takes a modest step in this direction [29]. In the next section, this paper reports the findings of our ongoing research with recent investigations on mobile payment influencing factors, and these have resulted in proposing a strategic framework for mobile payments in the subsequent section.

\section{InfluenCing Factors For Mobile Payments}

Although some industries such as, retail, entertainment and banking have been successfully adopting mobile options for billing and payment in certain countries, many industries are still cautious in offering mobile payment methods for their customers. This is partly because there are several issues related to mobile payments in an enterprise. On analysing the influencing factors, these could be broadly classified under three main dimensions:

- mobile payment players,

- payment methods

- $\quad$ enabling wireless technologies and

- social marketing.

\section{Mobile Payment Players}

There are many parties or players contributing to the mobile payment value chain. In order to access a payment service, a user or subscriber initially has to come into an agreement with a network provider for accessing telecommunication and the payment services provided by the specific operator. If mobile internet is used, an additional contract between a subscriber and an ISP is required. However, with the introduction of $3 \mathrm{G} / 4 \mathrm{G}$ technologies, mobile internet could be accessed directly through their mobile operator. Recent evolutions have enabled users to adopt new mobile payment and billing models for accessing various networks and services independent of the network provider [5][27]. In Table 1, we have summarised a list of players involved in influencing mobile payments in businesses.

Table 1. Mobile Payment Players and Influencing Factors

\begin{tabular}{|l|l|}
\hline \multicolumn{1}{|c|}{ Mobile Payment Players } & \multicolumn{1}{c|}{ Influencing Factors } \\
\hline $\begin{array}{l}\text { Equipment / device } \\
\text { manufacturers }\end{array}$ & $\begin{array}{l}\text { Device usability, features \& constraints, Wireless } \\
\text { technology, Native software, use of third party H/W and } \\
\text { S/W }\end{array}$ \\
\hline Network service providers & $\begin{array}{l}\text { Telecommunication infrastructure, Billing models and } \\
\text { contracts, Integration with payment service providers, QoS, } \\
\text { Network interoperability and Security }\end{array}$ \\
\hline Financial service providers & $\begin{array}{l}\text { Types of e-cash systems, Credit systems, Security and } \\
\text { Payment settlement }\end{array}$ \\
\hline Payment service providers & Interfacing (S/W, H/W and other players), Security and Cost \\
\hline $\begin{array}{l}\text { Market regulators and } \\
\text { consortiums }\end{array}$ & $\begin{array}{l}\text { Governing laws (bank, government and other agencies), } \\
\text { Rights protection, Price regulations and Tax policies }\end{array}$ \\
\hline
\end{tabular}


The abovementioned players need not be exactly mapped onto various business parties but could be an aggregation of business entities. For instance, the network service provider could be aggregating the services of mobile network operators, content providers and Internet service providers. Alternatively, there are cases where the network operator covers the functionality of an Internet service provider, while the content provider caters to payment services as well. A recent study [15] shows that a variety of mobile payment providers compete for consumers' attention with an evolution of merchant wallets, in-app payments and issuer wallets (Fig. 1). Proprietary mobile payment solutions are now being introduced as issuer wallets to compete with device manufacturers such as Apple, Samsung, etc. Hence, an evolution of such industry players have a major influence on the consumer adoption of mobile payments.

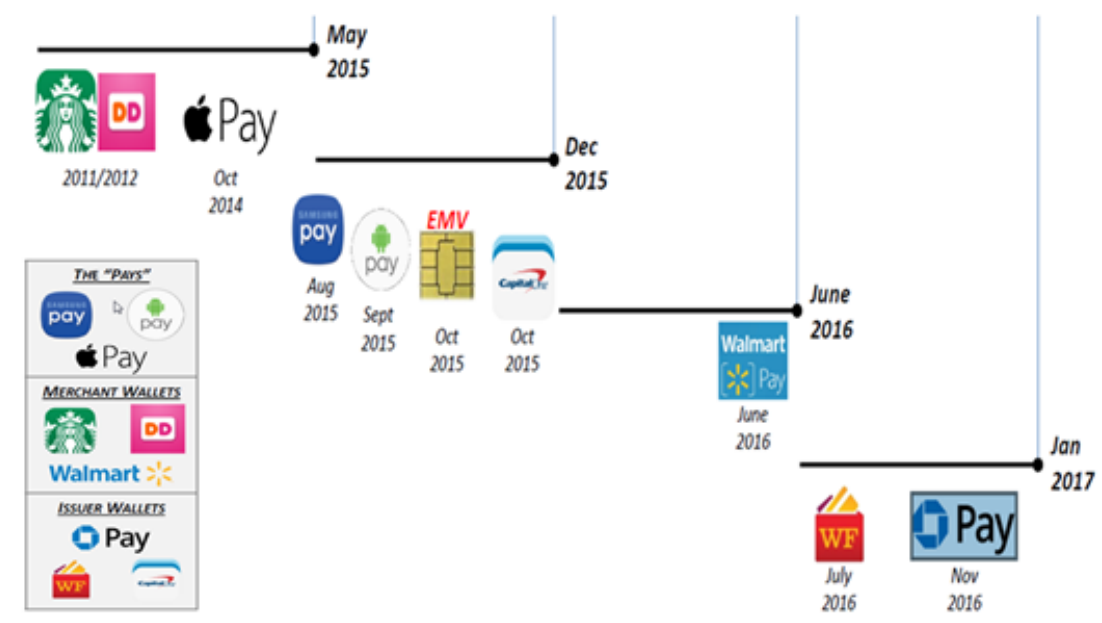

Fig. 1. Recent evolution of successful m-wallet players

\section{Payment Methods}

Though mobile payment services were traditionally managed by mobile network operators for many years using player-centric models, recently we find the emergence of new payment and billing models that allow consumers to access the payment services independent of who the owner of the service is [13][30]. The various types of payment methods supported by the mobile transactions further compounds the issue of mobile payment adoption. Commonly used payment methods include pre-paid cash card, micro-billing, person-to-person (P2P) and credit card payments. Some of the main factors that influence these payment methods in $\mathrm{m}$-commerce are identified in Table 2.

Table 2. Payment Methods and Influencing Factors

\begin{tabular}{|l|l|}
\hline \multicolumn{1}{|c|}{ Payment Methods } & \multicolumn{1}{c|}{ Influencing Factors } \\
\hline Pre-paid cash card & $\begin{array}{l}\text { Small transaction amount, Top-up methods and Availability } \\
\text { to anyone }\end{array}$ \\
\hline Micro-billing & Billing options, Service charge and Transaction maintenance \\
\hline Person-to-person (P2P) & $\begin{array}{l}\text { Direct credit or debit options, Service charge, Account } \\
\text { maintenance and Security }\end{array}$ \\
\hline Credit card & $\begin{array}{l}\text { Service provider trust, M-wallets (H/W and S/W integration) } \\
\text { and Security }\end{array}$ \\
\hline
\end{tabular}

Similar to Internet-based online payment methods that support pre-paid (debit) and post-paid (credit) services, mobile payments require an integrated flexible model that support quality of service (QoS) with one-stop billing schemes for the end-users [21]. The European Payment 
Council (EPC) has recently studied the use of Single Euro Payments Area (SEPA) mobile payment methods such as SEPA Card Payment (SCP) SEPA Direct Debit (SDD) and SEPA Credit Transfer to support and promote European payments integration and development [30]. From Fig. 2, we find that majority of the business models (B2B, B2C) have a low/medium focus in adopting SEPA enabled mobile payment methods for both proximity and remote types. While $\mathrm{C} 2 \mathrm{C}$ and $\mathrm{C} 2 \mathrm{~B}$ business models exhibit high focus for both proximity and remote SCP type of payments, SCT is preferred only for remote payments. From the universal low focus of direct debit type of mobile payments in all business models, we can infer that banks have not integrated well with SEPA enabled mobile payments. Hence, the various payment methods and their influencing factors need to be considered in arriving at a viable strategy to improve the adoption of mobile payments.

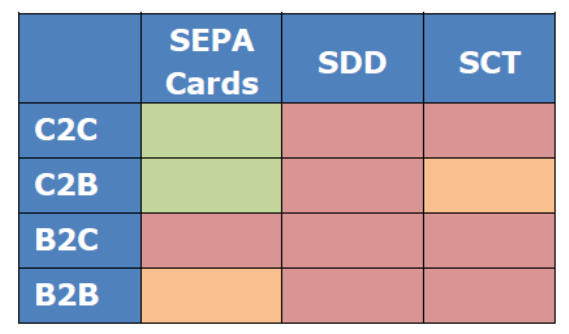

(a) Mobile proximity payments

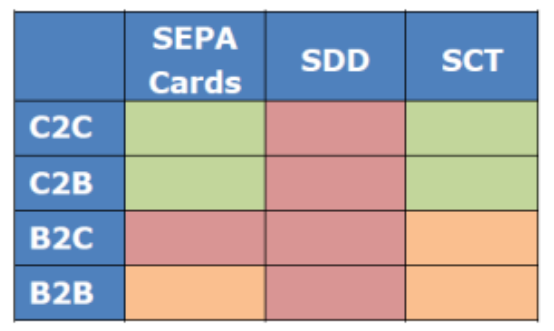

(b) Mobile remote payments

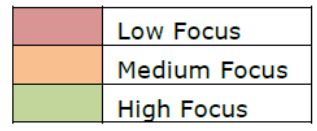

High Focus

Fig. 2. Trends in the usage of SEPA enabled payment methods

\section{Enabling Wireless Technologies}

The aforesaid payment methods could be adopted to make mobile payment transactions using different wireless technologies. Such mobile payments go through a set of wireless security levels which is a key factor in providing consumer trust and confidence [31]. The enabling wireless technologies could support mobile security elements that are either removable or nonremovable from the mobile device [24]. Removable security elements could be a single chip, a dual chip or a dual slot, while non-removable security elements could support embedded hardware and software modules, including personalised biometric technologies [13]. In table 3, we identify a list of wireless technologies commonly adopted in businesses and their influencing factors for mobile payment adoption.

Table 3. Enabling Wireless Technologies and Influencing Factors

\begin{tabular}{|l|l|}
\hline Enabling Wireless Technologies & \multicolumn{1}{c|}{ Influencing Factors } \\
\hline $\begin{array}{l}\text { Radio Frequency Identification } \\
\text { (RFID) }\end{array}$ & $\begin{array}{l}\text { Transponder \& reader frequencies / range, Encryption } \\
\text { methods and Payment methods }\end{array}$ \\
\hline Short Message Service (SMS) & $\begin{array}{l}\text { SMS gateway QoS, Payment methods, Merchant port ID } \\
\text { and Push technology }\end{array}$ \\
\hline $\begin{array}{l}\text { Wireless Access Protocol } \\
\text { (WAP) using WIM chip }\end{array}$ & $\begin{array}{l}\text { Dual chip phones, WIM certificate, Payment methods, } \\
\text { Security and Account Maintenance }\end{array}$ \\
\hline Infrared (IR) & Point-to-point range, Fault-tolerance and Payment methods \\
\hline Bluetooth & Security, Transmission time and Data volume \\
\hline $\begin{array}{l}\text { Near Field Communication } \\
\text { (NFC) }\end{array}$ & $\begin{array}{l}\text { Tokenisation, Mobile phones, NFC reader, Payment } \\
\text { methods }\end{array}$ \\
\hline Internet & $\begin{array}{l}\text { Mobile Apps for Payments, M-wallets, Security, Payment } \\
\text { Methods, Account Maintenance \& Fees }\end{array}$ \\
\hline
\end{tabular}


A mobile payment system typically espouses several wireless technologies with different possible payment methods and with different player-centric influencing factors. With security being a major concern in mobile payments, security modules with digital signatures are being implemented in the form of WAP Identity Module (WIM) cards. From traditional, simple Interactive Voice Response (IVR) systems adopted in phone banking to enhanced WIM chips in mobile devices and now with sophisticated mobile apps, the use of different wireless technologies involves different levels of security as the device moves in and out of multiple wireless networks leading to many security issues [17].

Recently, Quick Response (QR) Code is widely used in mobile payments [13][31] as the twodimensional label contains information about the item to which it is attached. Various types of QR codes based on the purpose such locating a building or describing material inventory or providing URL details, etc are utilised such that smartphone users can read the label and follow the information accordingly. While QR codes have limitations in terms of personalisation, Bluetooth low energy (BLE) beacons outperform QR codes in situations where leveraging personalised or contextual data is important. Hence, various innovations and advancements in the enabling wireless technologies could impact on their operations that could form major influencing factors for mobile payment adoption.

\section{Social Marketing}

Mobile payments through social marketing are being adopted to engage with customers, suppliers and stakeholders in new ways. For example, in China, a social platform, WeChat has connected its payment systems 30 million merchants through concerted marketing and opening up its APIs. The digitisation of business-to-person (B2P) and government-to-person (G2P) payments in agriculture and rural areas is emerging to include payments through mobile money that would benefit farmers and villagers who remain unbanked in developing countries.

Table 4. Social Marketing and Influencing Factors

\begin{tabular}{|l|l|}
\hline \multicolumn{1}{|c|}{ Social Marketing } & \multicolumn{1}{c|}{ Influencing Factors } \\
\hline Location Based Marketing & $\begin{array}{l}\text { Mobile Apps, Geospatial services, Security, Trust, Speed } \\
\text { and M-banking }\end{array}$ \\
\hline Push Offers and Coupons & $\begin{array}{l}\text { Social subscription, Loyalty programs, Tags and codes, } \\
\text { Payment methods }\end{array}$ \\
\hline Government Based Incentives & $\begin{array}{l}\text { Integrated services, SIM registration, Payment methods, } \\
\text { Security and M-banking }\end{array}$ \\
\hline Personalised Services & $\begin{array}{l}\text { Open APIs, Recommender features, M-wallets and Ease- } \\
\text { of-use }\end{array}$ \\
\hline
\end{tabular}

With current 4G network capabilities and the future expected 5G networks in the next couple of years' time, the ubiquity, speed and affordability of mobile technology provides a good avenue to promote mobile payments through social lives of consumer subjects in enhancing social and economic development. However, the lack of standardisation in the enabling wireless technologies, innovative payment method offerings and new mobile players with open APIs are resulting in a very fragmented approach worldwide. In table 4 we have identified some of the social marketing types and the influencing factors for mobile payment adoption.

\section{Mobile Payment Strategies}

A closer look into mobile payment activities taking place worldwide reveals future trends in the wireless and mobile Internet payment services [32][33][34]. A survey conducted in United States indicate that smartphone users making mobile payments increased to 28 percent more than previous two years and mobile payments are now attributing towards further growth [35]. 
Though m-commerce has a positive outlook from such studies, the path to the success of mobile payments is quite challenging with the ramifications of four main mobile payment dimensions and their influencing factors as identified in Section 3. The GSMA Digital Identity programme is working with mobile operators, governments and the development community to accelerate lifeenhancing mobile payment services for a more sustainable social and commercial impact [8].

Choosing the right type of mobile payment solution for an enterprise is a multi-criteria decision making process. Businesses and consumers require a practical framework to compare the various mobile payment solutions available in the market to meet their objectives. In this section, a framework for analysing the four dimensions with an integrated approach for adopting the right set of mobile payment solutions is presented in Fig. 4.

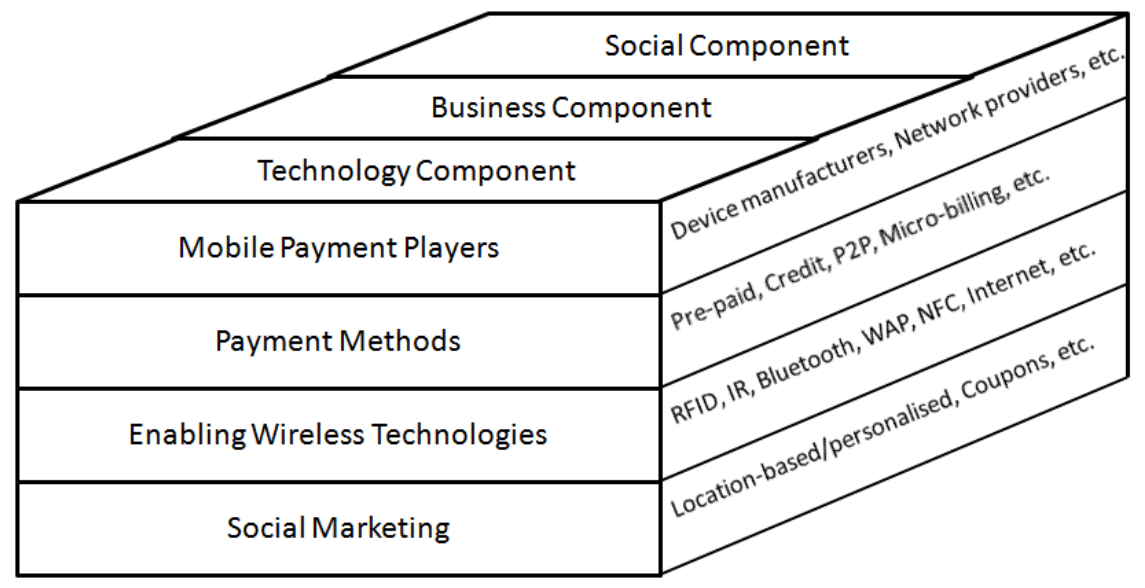

Fig. 4. A Framework with an integrated approach mobile payment adoption

The proposed framework consists of three components, namely technology component, business component and social component as shown in Fig. 4. The technology component of the framework helps the businesses and consumers to evaluate the various mobile payment solutions available in the market with regard to their underlying wireless technologies and their capabilities. The business component of the framework maps the various mobile payment solutions with the associated business players. Finally, the social component of the framework mainly helps different stakeholders to embrace social marketing and feedback techniques such as crowd sourcing for a successful adoption of the right mobile payment solution, taking into consideration its motivators and inhibitors derived from the technology and business components. To apply this framework for adopting the mobile payments, the following steps form the required guidelines:

Step 1: Identify all the mobile payment solutions available in the market. Prepare a comparison matrix based on the wireless technologies and the type of payment methods they support. There are various decision criteria associated with the technology that influence businesses as well as consumers in adopting a payment solution. These include the type of payments a mobile solution supports, the costs involved, how efficient is the transaction in terms of speed and fault-tolerance and the level of privacy and security it provides [36]. This step involves identifying the required service options offered in the following mobile payments and evaluating each solution option that supports them:

- Mobile banking (eg. Access bank account, Conduct bank transactions, Receive alerts, Receive statements, etc.)

- Mobile commerce (eg. Remote payments, Proximity payments, etc.)

- Mobile money transfers (eg. P2P money transfers, Airtime top-up, etc.) 
This step forms the technology component of the framework as it compares different payment solutions that could be adopted by various types of businesses and consumers, based on the underlying factors associated with wireless technologies and payment methods.

Step 2: Identify all the players associated with each mobile payment solution.

Prepare a comparison matrix based on the actors or mobile payment players involved in the payment solutions and the type of businesses they support. During the comparison process of the framework, identifying the type of businesses each payment solution supports and their stakeholder relationships with banks would help to identify the payment business models that suit the business type [37]. For example, a service-type business could use mobile payment solutions for car park / library fee payment or a merchant-type business could adopt these at retail point-ofsale (POS) terminals. The various mobile system business players determine the type of business model adopted by the payment solution. For example, a network operator-centric business model may involve businesses and consumers to be tied up with the network service provider who takes up an aggregator role for billing and charging. On the other hand, in a payment service-centric business model, the payment service is offered by independent providers who make the mobile payment service available to mobile subscribers, as they would be in commercial agreement with financial service providers as well as network service providers. In such situations, users are required to subscribe with the network provider as well as the payment service provider and businesses are required to liaise with the payment service providers and the associated players such as financial service providers and consortiums. Table 5 provides a comparison matrix of three different mobile payments (NFC based, code based and cloud based) from business viewpoints as an example

\begin{tabular}{|c|c|c|c|}
\hline & NFC & Code-Based & Cloud-Based \\
\hline Examples & Google Wallet, Isis & Starbucks, LevelUp, MCX & PayPal, Square Wallet \\
\hline $\begin{array}{l}\text { Required Investment: } \\
\text { Consumer }\end{array}$ & $\begin{array}{l}\text { Moderate: } \\
\text { NFC-enabled } \\
\text { smartphone }\end{array}$ & $\begin{array}{l}\text { Minimal: } \\
\text { Smartphone }\end{array}$ & $\begin{array}{l}\text { Minimal: } \\
\text { Smartphone }\end{array}$ \\
\hline $\begin{array}{l}\text { Required Investment: } \\
\text { Merchant }\end{array}$ & $\begin{array}{l}\text { Significant: } \\
\text { NFC-capable POS } \\
\text { terminals; } \\
\text { Software installation } \\
\text { and integration with } \\
\text { accounting system }\end{array}$ & $\begin{array}{l}\text { Moderate: } \\
\text { QR code scanners; } \\
\text { Software installation and } \\
\text { integration with account- } \\
\text { ing system }\end{array}$ & $\begin{array}{l}\text { Moderate: } \\
\text { Software installation and } \\
\text { integration with account- } \\
\text { ing system }\end{array}$ \\
\hline $\begin{array}{l}\text { Business Models: } \\
\text { Participants }\end{array}$ & $\begin{array}{l}\text { Mobile wallet providers; } \\
\text { Hardware providers; } \\
\text { Tech providers; } \\
\text { App vendors; } \\
\text { Mobile network opera- } \\
\text { tors; } \\
\text { Card issuers/Networks; } \\
\text { Handset providers }\end{array}$ & $\begin{array}{l}\text { Mobile payment provider; } \\
\text { Hardware providers; } \\
\text { Tech providers; } \\
\text { App vendors }\end{array}$ & $\begin{array}{l}\text { Mobile payment } \\
\text { provider; } \\
\text { Tech providers; } \\
\text { App vendors }\end{array}$ \\
\hline $\begin{array}{l}\text { Business Models: } \\
\text { Coordination and } \\
\text { Collaboration besides } \\
\text { Merchants }\end{array}$ & Critical & Less important & Less important \\
\hline Funding Sources & $\begin{array}{l}\text { Debit, credit, and } \\
\text { prepaid cards }\end{array}$ & $\begin{array}{l}\text { Pre-funded accounts or } \\
\text { bank accounts }\end{array}$ & $\begin{array}{l}\text { Bank account and/or } \\
\text { debit, credit, and prepaid } \\
\text { cards }\end{array}$ \\
\hline
\end{tabular}

Table 5. Sample mobile payment comparison matrix involving key business players 
Step 3: Short-list those mobile payment solutions that meet the business objectives based on the wireless technology comparisons made in Step 1 as well as the business model comparisons made in Step 2. Next, from social viewpoints, a trial based on marketing offers or government initiatives to test these mobile payment solutions could be done before actually adopting it. The decision making draws inputs and experiences gained during the trial period so that issues that arise during the trial period could be settled before the actual mobile payment adoption. In this step, feedback from social media play a major role in identifying the motivators as well as inhibitors for each mobile payment solution.

\section{Conclusions}

The adoption of mobile payment is constricted by multi-faceted issues that can be approached from several angles. This paper identified four main dimensions such as mobile payment players, payment methods, enabled wireless technologies and social marketing, as well as their influencing factors for a successful mobile payment adoption. A strategic framework proposed comprised of three steps to evaluate these four dimensions and influencing decision criteria involved in mobile payments. Such a framework would facilitate consumers, businesses and researchers to consider the different mobile payment solutions, from technology, business as well as social perspectives for a successful adoption.

\section{REFERENCES}

[1] Koss, V., Miles, J. and Boyes, E. (2013). "M-commerce comes of age: Collaborate to succeed," Journal of Payments Strategy \& Systems, vol. 7, no. 1, pp. 50-60.

[2] Buhan, D., Cheong, Y.C. and Tan, C.L. (2002) "Mobile payments in m-commerce", Wireless Internet Centre Report, Gemini Ernst \& Young.

[3] Wyse, J.E. (2003) "Supporting m-commerce transactions incorporating locational attributes: an evaluation of the comparative performance of a location-aware method of locations repository management", International Journal of Mobile Communications, Vol. 1, Nos. 1-2, pp.119-147.

[4] Mathew M, Balakrishnan N, Pratheeba S (2010) "A study on the success potential of multiple mobile payment technologies.” In: Technology Management for Global Economic Growth (PICMET).

[5] Pukkasenung P. and Chokngamwong R. (2016) "Review and comparison of mobile payment protocol," J.J.(Jong Hyuk) Park et al. (eds.), Advances in Parallel and Distributed Computing and Ubiquitous Services, Lecture Notes in Electrical Engineering, Springer, pp 11-20.

[6] Lee, C.P., Warkentin, M. and Choi, H. (2004), "The Role of Technological and Social Factors on the Adoption of Mobile Payment Technologies", Proceedings of the 10th Americas Conference on Information Systems (AMCIS), New York, August, pp. 2781-2786.

[7] Kremers, R. and Brassett J. (2017) "Mobile payments, social money: Everyday politics of the consumer subject”, New Political Economy, DOI: 0.1080/13563467.2017.1306503.

[8] GSMA White Paper (2017), The Mobile Economy, GSMA.

[9] Anil, S., Ting, L.T., Moe, L.H. and Jonathan, G.P. (2003) "Overcoming barriers to the successful adoption of mobile commerce in Singapore", International Journal of Mobile Communications, Vol. 1, Nos. 1-2, pp.194-231. 
International Journal of Managing Information Technology (IJMIT) Vol.10, No.2, May 2018

[10] Elliott, G. and Tang, H. (2004) "The wireless mobile internet: an international and historical comparison of the European and American wireless application protocol (WAP) and the Japanese iMode service", International Journal of Information Technology and Management, Vol. 3, No. 2/3/4.

[11] EMV White Paper, (2017), Payment Tokenisation Specification, EMVCo.

[12] EY White paper (2017), Mobile money - the next wave of growth, Ernst and Young.

[13] BCG White Paper (2017), Digital Payments 2020, BCG Boston Consulting Group.

[14] Ondrus, J. and Pigneur, Y. (2006), "Towards a holistic analysis of mobile payments: a multiple perspectives approach", Electronic Commerce Research and Applications, 5(3), pp. 246-257

[15] Mobile Wallet Report (2017) Study Of Mobile Banking \& Payments, First Annapolis Consulting, Inc.

[16] Yuan, Y. and Zhang, J.J. (2003) "Towards an appropriate business model for m-commerce", International Journal of Mobile Communications, vol. 1, no. 1-2, pp.35-56.

[17] Hayashi, F. (2012). "Mobile payments: What's in it for consumers?", Economic Review, vol. 97, no. 1, pp. 35-66.

[18] Mallat, N. (2007), "Exploring consumer adoption of mobile payments - A qualitative study", The Journal of Strategic Information Systems, vol. 16, no. 4, pp. 413-432.

[19] Carton, F, Hedman, J, Dennehy, D, Damsgaard, J, Tan, K and McCarthy, J, B. (2012), "Framework for Mobile Payments Integration" The Electronic Journal Information Systems Evaluation vol. 15, no. 1 , pp. $14-25$.

[20] Ghosh, A. and Swaminatha, T. (2001) "Software security and privacy risks in mobile e-commerce", Communications of the ACM, vol. 44, no. 2, pp.51-57.

[21] Koutsopoulou, M. et al. (2004) "An integrated charging, accounting and billing management platform for the support of innovative business models in mobile networks", International Journal of Mobile Communications, vol. 2, no. 4, pp. 418-434.

[22] Fun TS, Beng LY, Razali MN (2013) "Review of mobile macro-payments schemes", Journal of Advances in Computer Networks, vol. 1, no. 4, pp. 323-328.

[23] Singh A, Shahazad KS (2012) A review: secure payment system for electronic transaction. International Journal of Advanced Research in Computer Science and Software Engineering, vol. 2, no. 3, pp. 236-243.

[24] Ahamad SS, Udgata SK, Nair M (2014) "A secure lightweight and scalable mobile payment framework" In: FICTA 2013. Advances in Intelligent System And Computing, vol. 247. Springer International Publishing, Switzerland, pp. 545-553.

[25] Venkatraman, S. (2008), "Mobile Payment Implementation - A Reference Framework", International Journal of Business Information Systems, vol. 3, no. 3, pp. 252-271.

[26] Au, Y.A. and Kauffman, R.J. (2008), "The economics of mobile payments: Understanding stakeholder issues for an emerging financial technology application", Electronic Commerce Research and Applications, vol. 7, no.2, pp. 141-164.

[27] Maurer, B. (2012), "Mobile money: Communication, consumption and change in the payments space", Journal of Development Studies, vol. 48, no. 5, pp. 589-604. 
International Journal of Managing Information Technology (IJMIT) Vol.10, No.2, May 2018

[28] Xu, W. (2017), “The study of WeChat payment users willingness factor”, Journal of Service Science and Management, vol. 10, pp. 251-259.

[29] Venkatraman, S. (2018), “Analysis of mobile payment influencing factors", Proceedings of 8th International Conference on Computer Science, Engineering and Applications (ICCSEA 2018), Melbourne.

[30] EPC White Paper (2017), Mobile Payments, European Payment Council, EPC492-09 v5.0, pp. 1-105.

[31] PwC White Paper (2017), Mobile Payment Report 2017, Price Waterhouse Coopers.

[32] SWIFT White Paper (2012), Mobile Payments, SWIFT.

[33] Crowe, M., Rysman, M. and Stavins, J. (2010) "Mobile Payments at the Retail Point of Sale in the United States: Prospects for Adoption," Review of Network Economics, vol. 9, no. 4. Digital Research Inc.

[34] UNCTAD (2012), "Mobile Money for Business Development in the East African Community: A Comparative Study of Existing Platforms and Regulations" United Nations Report, Geneva.

[35] Federal Reserve System. (2015), "Consumers and Mobile Financial Service 2015," Board of Governors of the Federal Reserve System, Washington D.C.

[36] Jonker, N. (2011), “Card acceptance and surcharging: The role of costs and competition," Review of Network Economics, vol. 10, no. 2, pp. 1-35.

[37] GSMA White Paper (2011), Mapping and Effectively Structuring Operator- Bank Relationships to Offer Mobile Money for the Unbanked, GSMA.

\begin{abstract}
AUTHORS
Dr. Sita Venkatraman earned her PhD in Computer Science, with a doctoral thesis titled "Efficient Parallel Algorithms for Pattern Recognition", from National Institute of Industrial Engineering in 1993. In the past 30 years, Sita's work experience involves both industry and academics - developing turnkey projects for IT industry and teaching a variety of IT courses for tertiary institutions, in India, Singapore, New Zealand, and more recently in Australia since 2007. She currently works as Senior Lecturer (Information Technology) at the School of Engineering, Construction \& Design, Melbourne Polytechnic, Australia. She also serves as Member of Register of Experts at Australia's Tertiary Education Quality and Standards Agency (TEQSA).
\end{abstract}

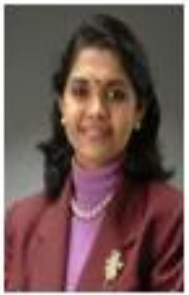

Dr. Venkatraman's. recent research areas are predominantly in Business Intelligence, Data Mining, Cloud Computing, Information Security and Health Informatics. She has published eight book chapters and more than 120 research papers in internationally well-known refereed journals and conferences. 
International Journal of Managing Information Technology (IJMIT) Vol.10, No.2, May 2018 